\title{
Flow-Through Reaction in Palladium- Supported Microreactors
}

Polymer-Supported Synthesis

Key words

microreactor

microflow reactor

flow-through

reactor

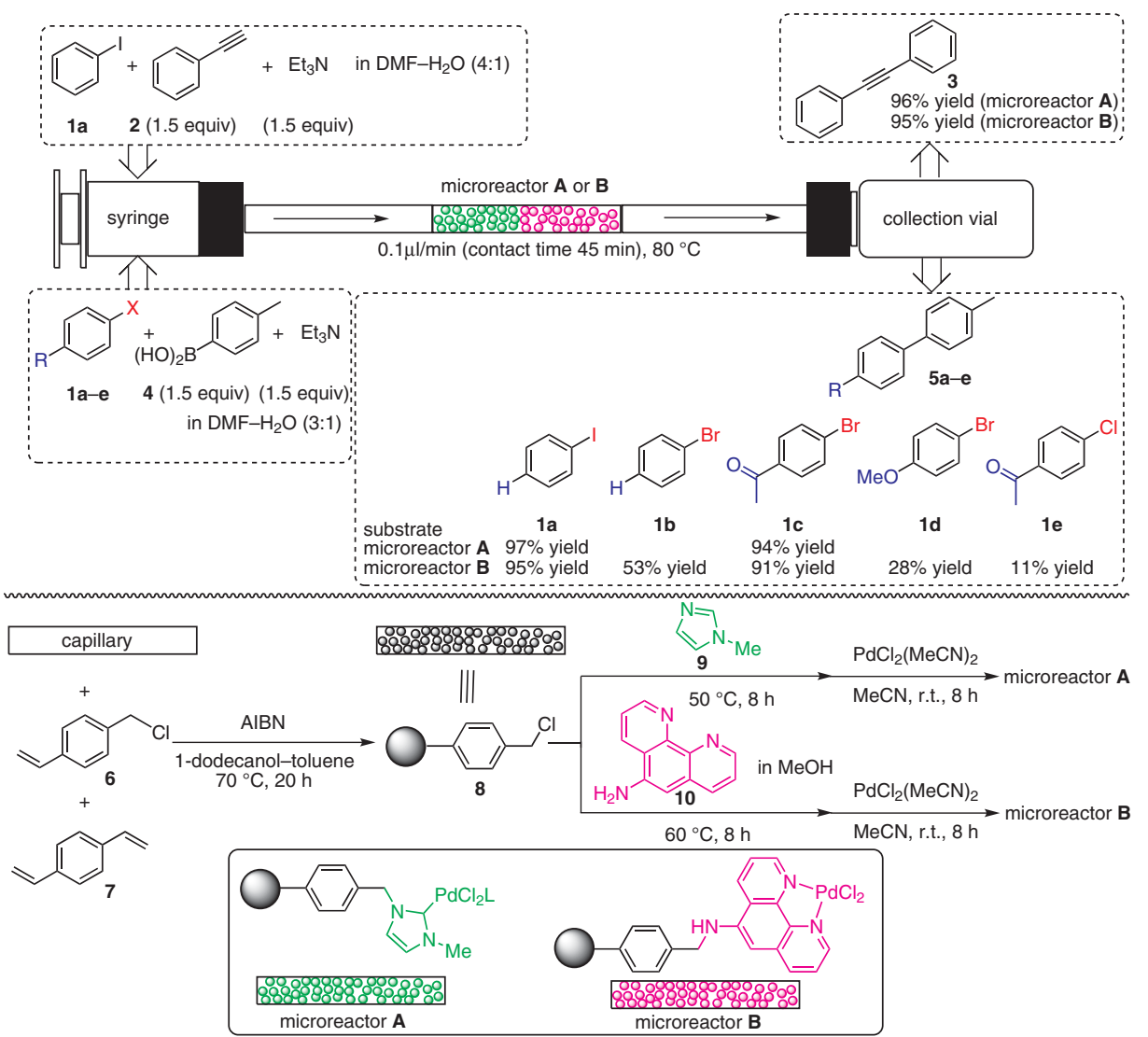

Significance: The authors reported the Sonogashira and the Suzuki-Miyaura reaction performed with microflow reactors filled with palladium polymer ( $\varnothing 250 \mu \mathrm{m}$, length $5 \mathrm{~cm}$ ). Thus, the Sonogashira reaction of iodobenzene (1a) and phenylacetylene (2) was carried out with the microreactor $\mathbf{A}$ or $\mathbf{B}$ to give diphenylacetylene (3) in 96\% (with A) or 95\% yield (with B), respectively. The Suzuki-Miyaura reaction of aryl halides $\mathbf{1 a - e}$ with 4-tolylboronic acid (4) gave the corresponding biphenyls 5a-e under similar flow-reaction conditions in 11-97\% yield.
Comment: Chloromethylstyrene (6) and divinylbenzene (7) were polymerized inside a capillary [pretreated with 3-(trimethoxysilyl)propyl methacrylate] in the presence of a porogen (toluenedodecanol) and AIBN to afford a polymer-installed capillary $\mathbf{8}$. The capillary $\mathbf{8}$ was subsequently treated with the ligand precursor [1-methylimidazole $\mathbf{9}$ (for A) or 5-amino-1,10-phenanthroline 10 (for $\mathbf{B}$ )] and $\mathrm{PdCl}_{2}(\mathrm{MeCN})_{2}$ to give the reactive capillary $\mathbf{A}$ and $\mathbf{B}$. 